\title{
MODELING THE VERTICAL TRANSMISSION OF SYPHILIS
}

MODELANDO A TRANSMISSÃO VERTICAL DA SÍFILIS

\section{DOUGLAS S. DE ALBUQUERQUE ${ }^{a} \quad$ CLAUDIA M. DIAS ${ }^{b}$}

\begin{abstract}
A Modelagem Matemática da Sífilis pode ser usada para entender melhor sua transmissão em uma população e o ressurgimento da sífilis em países como o Brasil, onde atualmente se observa um considerável aumento de casos. Então, baseado nos modelos matemáticos disponíveis na literatura, este trabalho propõe uma aplicação prática para o cenário brasileiro e, ainda, apresenta uma extensão que inclui a possibilidade de transmissão vertical (de mãe para filho) da doença.
\end{abstract}

Palavras-chave: Modelagem Matemática, Propagação da Sífilis, Transmissão Vertical.

\begin{abstract}
Mathematical Modeling of Syphilis can be used to better understand its transmission in a population and the resurgence of syphilis in countries like Brazil, where there is currently a considerable increase in cases. So, based on the mathematical models available in the literature, this work proposes a practical application for the Brazilian scenario, and still presents an extension that includes the possibility of vertical transmission (from mother to child) of the disease.
\end{abstract}

Keywords:Mathematical Modeling, Syphilis Propagation, Vertical Transmission.

MSC2020: 34N99, 92B05

\footnotetext{
${ }^{a}$ Universidade Federal Rural do Rio de Janeiro, Departamento de Tecnologias e Linguagens, Nova Iguaçu, Brasil; ORCID:https://orcid.org/0000-0001-6505-1552 E-mail: dougdealbu@gmail.com

${ }^{b}$ Universidade Federal Rural do Rio de Janeiro, Programa de Pós-graduação em Modelagem Matemática e Computacional, Nova Iguaçu, Brasil; ORCID:https://orcid.org/0000-0001-7376-1554 E-mail: mazzaclaudia@gmail.com
} 


\section{Introduction}

Syphilis is a human infection disease transmitted through sexual contact, so can be considered a Sexually Transmitted Disease (STD). It is caused by the bacterium Treponema Pallidum and it's among the major causes of illness in the world, and a serious public health problem in developing countries [26], although the first recorded outbreak of syphilis in Europe occurred in 1494/1495 in Italy during a french invasion [9]. By that time it was known as "French Disease". In 16th to through 19th centuries, syphilis was one of the largest public health burdens in prevalence, symptoms and disability [16]. In 20th century the treatment suffer a great improvement with the advances in microbiology and pharmacology. Its important to note penicillin was discovered in 1928 increasing the effectiveness of treatment. The disease remain a challenging public health problem, specially in developing countries, as Brazil, where it is observed a number of recent cases including in pregnant women, identified during prenatal examinations [22]. The vertical transmission, from infected mother to fetus causes a congenital infection (infected inside the uterus), but contact with a genital lesion during birth can also transmit the infection [21].

In Brazil, there has been a significant increase in cases of acquired syphilis, as well as among pregnant women, in recent years. The Ministry of Health provided complete data from 2010 to 2019, and on the first half of 2020 [23]. Figure 1 shows the evolution of cases among pregnant women in Brazil. It is observed that 61,127 cases (20.8 / 1,000 live births) have been registered in 2019, and in the first half of 2020 there were already 24,189 new cases. Most cases were detected during prenatal examinations. Figure 2 shows the evolution of cases of congenital syphilis, which follows the same upward trend. And Figure 3, provides information on the deaths of children under 1 year of age due to congenital syphilis from 2010 to 2019. All of this information based on [23], raises great concerns and needs to be studied seriously.

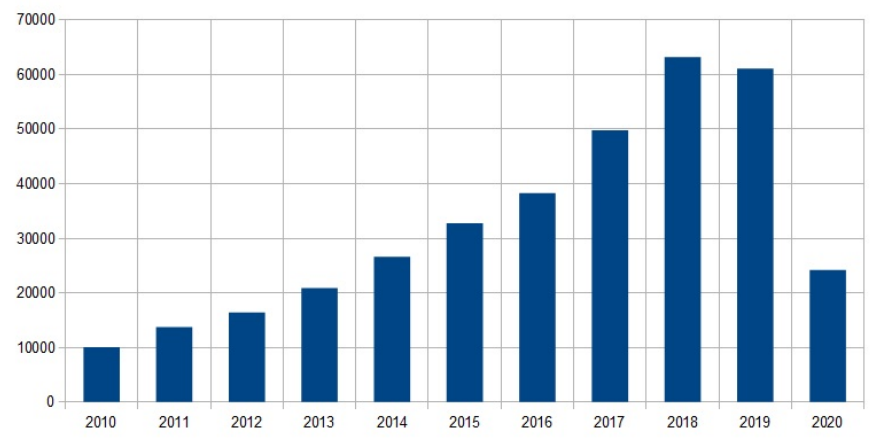

Figure 1: Pregnant women with syphilis 2010-2020 (per 1,000 live births). Source: [23]. 


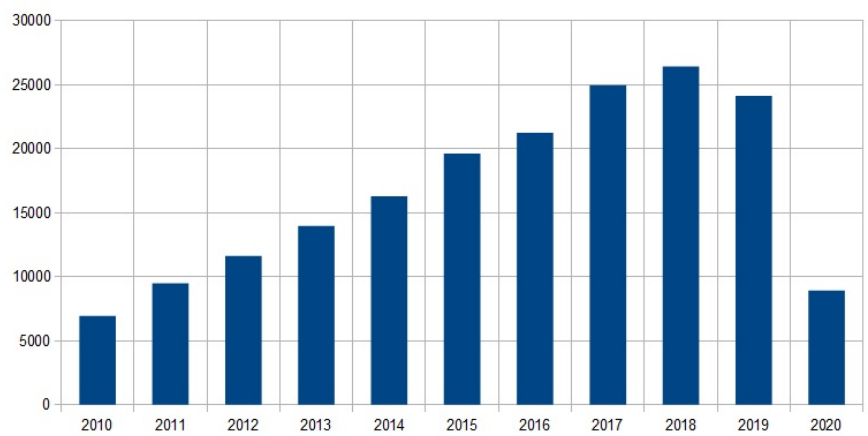

Figure 2: Congenital syphilis in children under one year of age 2010-2020 (per 1,000 live births). Source: [23].

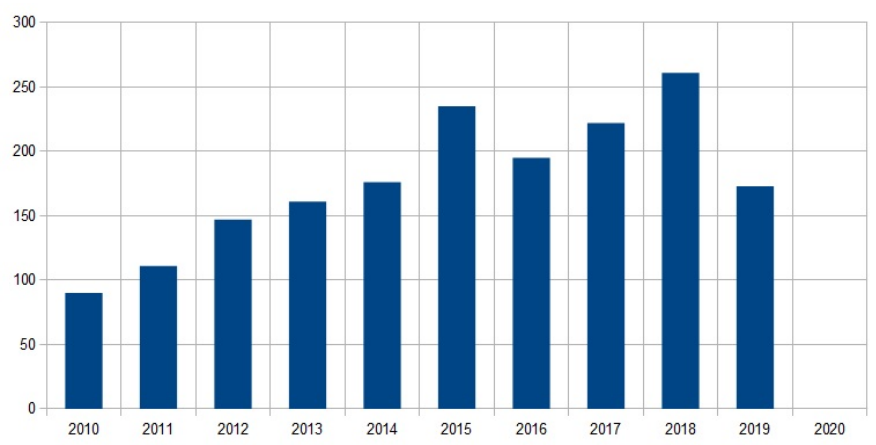

Figure 3: Deaths due congenital syphilis in children under one year of age 2010-2019 (per 100,000 live births). Source: [23].

According Avelleira and Bottino [2], embryo infection can occur at any stage gestational age or stage of maternal illness. The main factors that determine the probability of transmission are the stage of syphilis in the mother and the exposure of the fetus in the womb. Therefore, transmission will be greater in the early stages of the disease, when there is more spirochetes in the circulation. The transmission rate is $70-100 \%$ in the primary and secondary phases, $40 \%$ in the recent latent phase and $10 \%$ in the late latent phase. Contamination of the fetus can cause abortion, fetal death and neonatal death in $40 \%$ of infected concepts or the birth of children with syphilis. Approximately 50\% of infected children are asymptomatic at birth. The risk of contagion varies from $10 \%$ to $60 \%$ according to most authors [2]. Incidence rate of congenital syphilis in children under 1 year of age is about 8.383 (per 1,000 live births) [20] . Average mortality rate (non-congenital) per 1,000,000 inhabitants is 0.156 [17] and for congenital syphilis is 3.716 per 100,000 inhabitants. All this information reinforces the need to study vertical transmission of the disease. One way to do this is through mathematical modeling.

In the paper published in 1997, Garnett et al. [10] proposed a mathematical 
model that admits multiple stages of infection, where the individual when treated in the latent or tertiary stages acquires temporary immunity. The work published by Grassly et al. [11], in 2005, uses real data on syphilis cases between 1941 and 2002 for 68 cities in the United States with a SIRS (Susceptible - Infected - Recovered Susceptible) model. Additionally, Milner and Zhao [19], in a 2010 article, proposed a model that considers behaviors, such as safe sexual activity, to control the epidemic, and emphasize that secondary and later infections confer partial immunity to the individual. In a 2016 study, Iboi and Okuonghae [14] presented a new deterministic mathematical model that addresses the distinction between early and late latent stages, in addition to considering that there have a reversal for individuals infected in the early latent stage to the primary or secondary stages of the infection. In 2018, Gumel et al. [12] presented a deterministic sex-structured mathematical model of the population and Okuonghae et al. [24] developed a new mathematical model that allow preventive strategies against the spread of syphilis. Abdullahi et al. [1] develop a non-linear mathematical model for the transmission of syphilis. The goal of the authors was analyze the existence and uniqueness of the system of equations using the Lipchitz criteria [4]. In this context, mathematical modeling can be used to better understand the transmission in a population and the resurgence of syphilis in countries as Brazil. So based on Abdullahi et al. model, this work proposes a practical application of the model in Brazilian scenario, and its extension to include vertical transmission of the disease. The next section will deal with the model proposed by [1] and its application. In section 3, we will present the new model with vertical transmission. Tests are performed to observe the dynamics of infection in the population. Finally, some discussions will be held on the results obtained.

\section{Mathematical model for syphilis}

The original model [1] sub-divides the population into different components or compartments: Susceptible male $\left(S_{m}(t)\right)$, Susceptible female $\left(S_{f}(t)\right)$, Infected male $\left(I_{m}(t)\right)$, Infected female $\left(I_{f}(t)\right)$, Complications $(C(t))$ and Treated $(T(t))$, such that, $t$ represents the time. The model assumes the following hypothesis:

- the six compartments sub-divides the total population $(N(t))$, i.e, $N(t)=$ $S_{m}(t)+S_{f}(t)+I_{m}(t)+I_{f}(t)+C(t)+T(t)$. In this way, the total population remains constant at every instant of time;

- the susceptible individuals have no contact with the infection until the sexual contact with infected individuals; 
- only the infected population who effectively contracted the infection, can transmit it through sexual contact;

- sexual contact between the same sex individuals will not be considered;

- infected individuals, either male or female, are equally likely to have contact with a susceptible individual;

- the individuals with medical complications have infection at a stage that can leads to other diseases or death;

- the treated population comprises the individuals recovered due treatment.

The corresponding mathematical model is given as:

$$
\begin{gathered}
\dot{S_{m}}=\pi_{1}-\alpha_{1} I_{f} S_{m}-\mu S_{m} \\
\dot{S}_{f}=\pi_{2}-\alpha_{2} I_{m} S_{f}-\mu S_{f} \\
\dot{I_{m}}=\alpha_{1} I_{f} S_{m}-\left(r_{1}+\beta_{1}+\mu\right) I_{m} \\
\dot{I_{f}}=\alpha_{2} I_{m} S_{f}-\left(r_{2}+\beta_{2}+\mu\right) I_{f} \\
\dot{C}=\beta_{1} I_{m}+\beta_{2} I_{f}-(\nu+\mu+\delta) C \\
\dot{T}=r_{1} I_{m}+r_{2} I_{f}+\nu C-\mu T
\end{gathered}
$$

The mathematical model presents as parameters the following positive constants: $\pi_{m}, \pi_{f}$ are recruitment rates for susceptible classes; $\alpha_{1}, \alpha_{2}$ are contact rates for male and female; $\beta_{1}, \beta_{2}$ are rate of progression of infected classes into the complication class; $r_{1}, r_{2}$ are recovery rates; $\nu$ is the treated rate of complications class; $\mu$ represents the natural death's rate; $\delta$ is the syphilis induced death's rate. The dynamic mechanism can be better understood through the scheme depicted at Figure 4.

Through this model the authors examined the existence and uniqueness of solution, showing that exists a possible invariant, and proved that the system (1)-(6) has a unique solution. However, as the model has not been tested or used in a practical situation, we propose the application of the model to the Brazilian scenario and also its modification to consider the vertical transmission of the infection.

\section{Model application to the Brazilian scenario}

As previously mentioned, one of the objectives of this work is to apply the model presented in the previous section to the Brazilian reality as a simulation scenario. In 


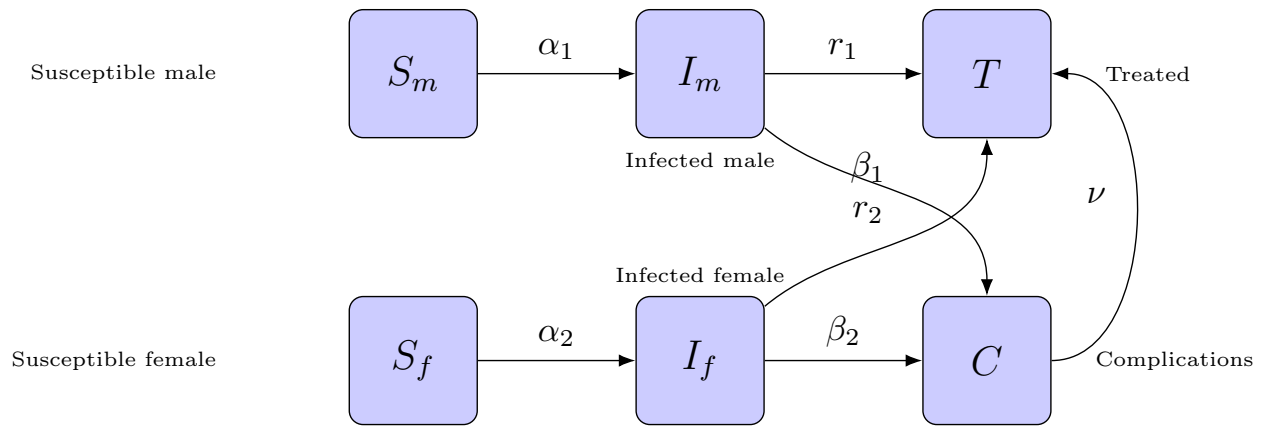

Figure 4: Diagram of the Original Model(without natural mortality and recruitment). Source: [1].

this context, extensive research was carried out in order to establish the data for the parameters used. We note that some information relevant to the implementation of the model is not available for public consultation. Therefore, it was necessary to estimate certain parameters. In addition, hypotheses were established in order to obtain the most realistic result possible. In effect, an initial population $(t=0)$ of susceptible people with 100 thousand inhabitants was assumed, such that active population in Brazil is divided approximately equally between men and women $\left(S_{m}(0)=S_{f}(0)=50,000\right)$. For the infected class, information was taken from [23], relating to the year 2017. As the intention was to observe the behavior of syphilis for a year, that is, the experiment tried to reproduce the dynamics of infection that occurred in 2018, the number of infected people was divided by 365 , thus obtaining the number of daily cases of infection. Even the relatively short time for studying cases of contamination by the disease justifies the choice of a model that does not consider the individual's reinfection. Finally, we sought to determine the number of people infected 10 days before the beginning of the analysis as an initial condition. So $I_{m}(0)=1,970$ and $I_{f}(0)=1,380$. It was also considered $C(0)=T(0)=0$.

The system of ordinary differential equations, was solved through the numerical method Runge-Kutta of Fourth Order [3] using the computational environment Scilabß). Computational tests were performed on a Dell Inspiron ( ), 3421 Intel Core i3-32171 CPU 1.80 Ghz and 4 Gb of RAM.

Male and female recovery rates were calculated as the average recovery time, considered equal for men and women and lasted 14 days. Thus, $r_{1}=r_{2}=1 / 14$ days $^{-1}$. The recovery rate for the complicated class was calculated in a similar way to the previous case, but with a recovery time of 21 days, that is, $\nu=1 / 21$ days $^{-1}$. Male and female contact rates, by hypothesis, were calculated from the incidence 
rate and the detection rate, according to [23]. Thus, $\alpha_{1}=0.10115 / 100,000$ inhab and $\alpha_{2}=0.06885 / 100,000$ inhab. Male and female progression rates were hypothesized considering that $10 \%$ of the infected population goes to the complicated class, and that, in general, women adhere better to treatment. Thus, $\beta_{1}=0.004286$ and $\beta_{2}=0.002857$. Finally, the mortality rate induced by syphilis was obtained in [17]: $\delta=0.0156 / 1,000,000$ inhab. Numerical tests do not consider vital dynamics because the relatively short observation time. Thus, $\pi_{1}=\pi_{2}=\mu=0$.

The Figure 5 reproduces the behavior of each population during the observed period of 1 year. The ordinate axis represents the number of individuals in each class and the abscissa axis the elapsed time in months. The downward trend of susceptible and infected populations along with the growth of the curve for the recovered population was already expected, because it is a $S I R$ [15] type model (SusceptibleInfected- Recovered), where populations migrate between compartments and the individual after recovery is no longer observed in the model. Finally, it is important to note that a chart was created to account for the accumulated cases of infected people. The goal was to compare the data obtained in the numerical experiment with real data. In fact, it was found in the simulation that after one year there would be an approximate value 105,000 or 110,000 infected men and 75,000 infected women. According to [23], in 2018 there were 94,715 infected men and 64,144 infected women, so the experiment obtained a very satisfactory result considering the uncertainties involved in the modeling and parameters adopted.

\section{A Modeling proposal for vertical transmission}

Three new compartments were created to include vertical transmission in the original model: Susceptible babies $\left(S_{b}(t)\right)$, Infected pregnant $\left(I_{p}(t)\right)$ and Infected babies $\left(I_{b}(t)\right)$. Thus, the new model is based on nine compartments that subdivide the total population $(N(t))$ at time $t$, so $N(t)=S_{m}(t)+S_{f}(t)+S_{b}(t)+I_{m}(t)+I_{f}(t)+$ $I_{p}(t)+I_{b}(t)+C(t)+R(t)$. In addition, some reservations were made in the original hypotheses:

- the class of pregnant infected will be formed only by individuals who have migrated from the female infected class;

- only the infected population who effectively contacted the infection, can transmit it through sexual contact or by vertical transmission. 

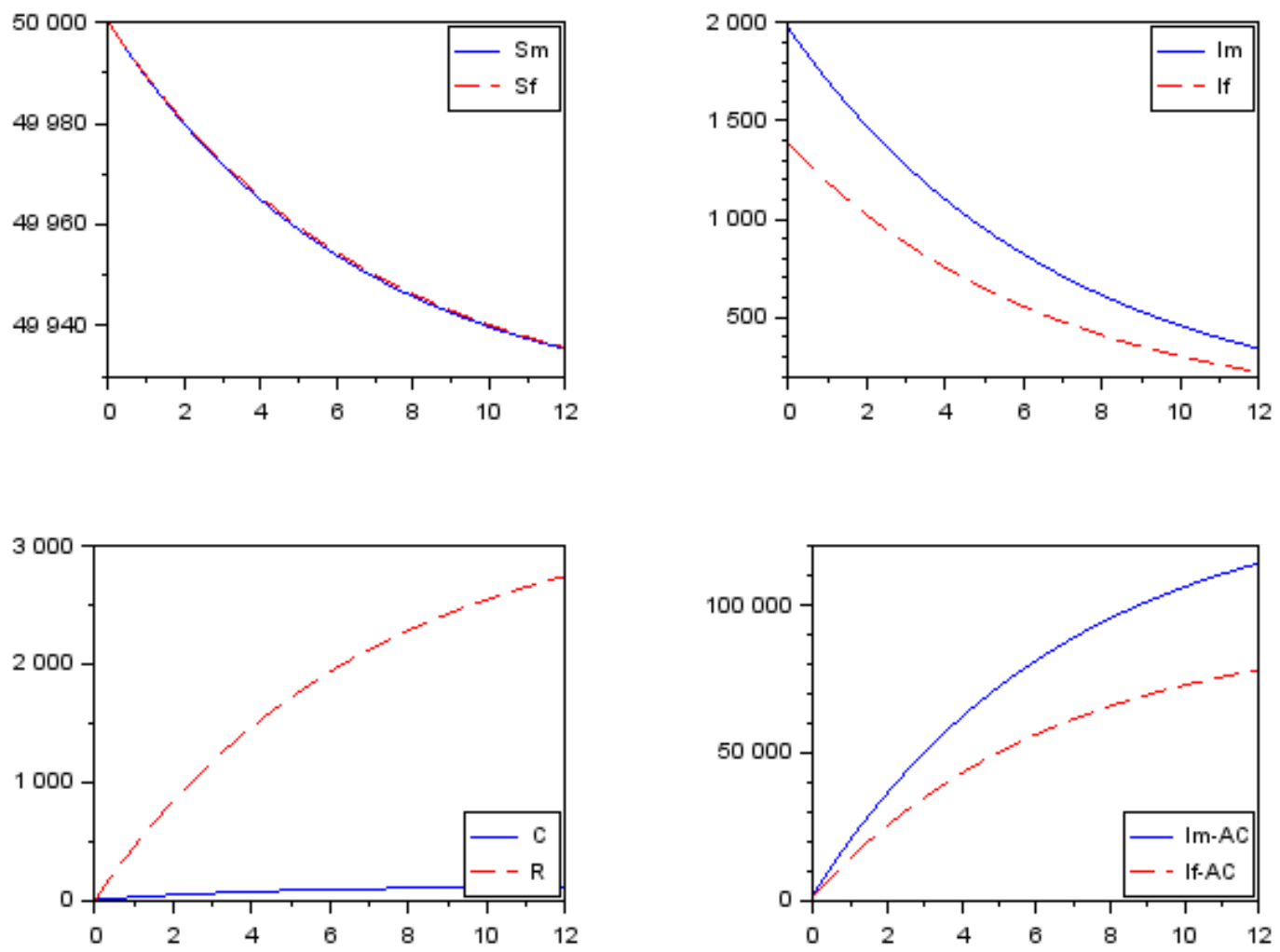

Figure 5: Numerical Solution for Acquired Syphilis Transmission Model to Brazil in 2018. Source: Authors.

The proposed model includes new parameters assumed as positive constants: the fertility rate $k$; contamination rate of babies born of infected mother $\bar{k}$; syphilis induced death rate for babies $\bar{\delta}$, as we can see in the corresponding mathematical model given as:

$$
\begin{gathered}
\dot{S}_{m}=-\alpha_{1} I_{f} S_{m} \\
\dot{S}_{f}=-\alpha_{2} I_{m} S_{f} \\
\dot{S}_{b}=(1-\bar{k}) I_{p} \\
\dot{I_{m}}=\alpha_{1} I_{f} S_{m}-\left(r_{1}+\beta_{1}\right) I_{m} \\
\dot{I_{f}}=\alpha_{2} I_{m} S_{f}-\left(r_{2}+\beta_{2}\right) I_{f} \\
\dot{I_{p}}=k I_{f}-\left(r_{2}+\beta_{2}\right) I_{p} \\
\dot{I}_{b}=\bar{k} I_{p}-\bar{\delta} I_{b} \\
\dot{C}=\beta_{1} I_{m}+\beta_{2} I_{f}+\beta_{2} I_{p}-(\nu+\delta) C
\end{gathered}
$$




$$
\dot{T}=r_{1} I_{m}+r_{2} I_{f}+r_{2} I_{p}+\nu C
$$

The figure 6 shows in a schematic way the transmission dynamics of the new model according to the equations described in (7)-(15).

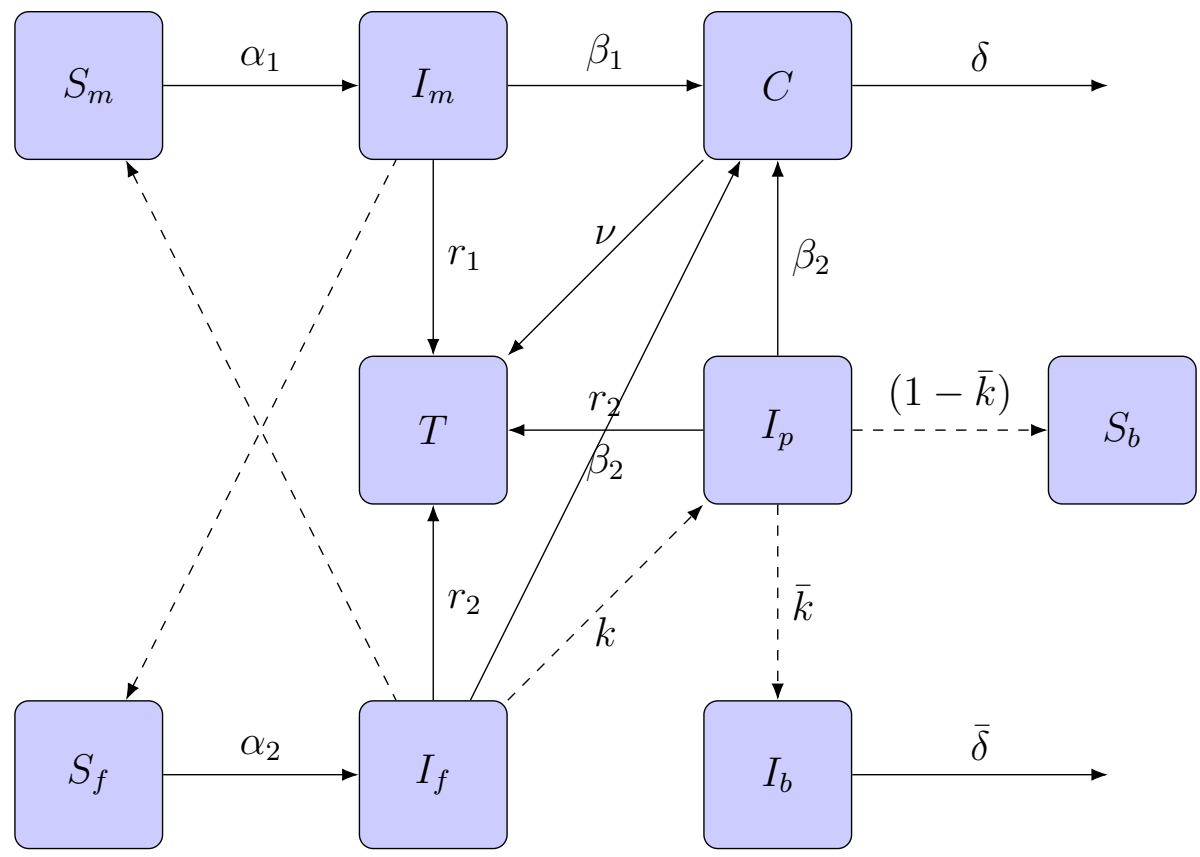

Figure 6: Diagram for Vertical Transmission Model. Source: Authors.

The infected female class was subjected to a fertility rate in order to estimate the infected pregnant class, who must generate susceptible or infected babies. From this, it became possible to observe the vertical transmission of syphilis, since it occurs from the infected mother to the fetus during pregnancy. In this way, the new model works as an extension of the original model, taking advantage of some parameters already established. It is important to mention that the original mathematical model does not contemplate sexual contact between individuals of the same sex. Once the objective of this work is to present a mathematical model that includes vertical transmission, it is not pertinent to observe this type of contact, since it does not influence the contagion in newborns.

\section{Model Analysis}

Once established the mathematical model, it is appropriate to consider their application as a strategy for the disease control, hence it is essential to study the basic reproduction number $\left(R_{0}\right)$. The $R_{0}$ is defined as the expected number of secondary infections produced by a typical infected individual in a susceptible population [5], 
i.e, it will be able to predict the beginning of a possible sickness outbreak in a population that has no infected individuals yet. So that, if $R_{0}>1$, then the number of infected individuals will increase with each generation and the disease will spread, but, if $R_{0}<1$, then each infected individual will produce less than one infected individual, therefore the infected individuals will disappear and the disease will be extinguished [7].

As been seen previously, the epidemiological model is applied to a heterogeneous population. Are set convenient parameters for the disease dynamics, so that it is possible to determine homogeneous sub populations, according to the way their individuals are classified. And segment these sub populations into a finite number of compartments [8], where individuals can migrate over time if their states change [6], generating a system of ordinary equations. From the complete system can be defined a subsystem called infected subsystem, which includes only the stages where there is the propagation of the disease, and thus, relate the number of recently infected individuals through the matrix known as the next generation matrix (NGM), usually referred as $K$ [6]. In fact, $R_{0}$ is defined as the spectral radius of the NGM and can be given as the dominant eigenvalue of $K$. To calculate $R_{0}$, it is necessary to linearize the infected subsystem over a state in which there are no cases of disease infection. From an epidemiological perspective, the linearization reflects the potential of an infection spread (which is assigned to $R_{0}$ ), when an infected individual is inserted into a totally susceptible population [6]. Hence, the linerization of the infected subsystem is the first step to calculate $R_{0}$.

The method for determining $R_{0}$ consists of decomposing the NGM as the Jacobian matrix $(T+\Sigma)$, where, $T$ is the transmission part, representing only the production of new infections, and $\Sigma$ is the transition part, representing all other states changes [6]. Thus, the matrix was structured through an epidemiological interpretation, which is the main objective to apply the NGM method. The decomposition of the epidemiological system into the matrices $T$ and $\Sigma$ was described by van den Driessche \& Waltmough in a paper published in 2002 [8].

So, NGM will be defined as

$$
K=-T \Sigma^{-1} .
$$


Let $\rho(k)$ the dominant eigenvalue of $K$, so $R_{0}$ can be defined as

$$
R_{0}=\rho(K)
$$

The NGM method follows three steps [6]:

1. decompose the infected subsystem as the Jacobian matrix $(T+\Sigma)$, where

- $T$ contains the entries corresponding to the transmission events and

- $\Sigma$ contains the entries corresponding to the state changes;

2. calculate NGM as $K=-T \Sigma^{-1}$;

3. determinate $\rho(K)$.

Assume the (1)-(6) system. Define $N_{1}$ and $N_{2}$ as the populations formed only by male and female individuals, respectively, then,

$$
N_{1}=S_{m}+I_{m}+\lambda_{1} C+\lambda_{2} T
$$

and

$$
N_{2}=S_{f}+I_{f}+\left(1-\lambda_{1}\right) C+\left(1-\lambda_{2}\right) T
$$

such that, $0 \leq \lambda_{1}, \lambda_{2} \leq 1$, so $N=N_{1}+N_{2}$. In addition, in the disease free stage: $I_{m}=I_{f}=C=R=0$, so

$$
N_{1}=S_{m} \text { and } N_{2}=S_{f} \Rightarrow N=S_{m}+S_{f}
$$

It is possible notice that there are three compartments in the (1)-(6) model with infectious individuals $\left(I_{m}, I_{f}\right.$ and $\left.C\right)$. Consider the following system of equations:

$$
\begin{gathered}
\dot{I_{m}}=\alpha_{1} I_{f} N_{1}-\left(r_{1}+\beta_{1}+\mu\right) I_{m} \\
\dot{I_{f}}=\alpha_{2} I_{m} N_{2}-\left(r_{2}+\beta_{2}+\mu\right) I_{f} \\
\dot{C}=\beta_{1} I_{m}+\beta_{2} I_{f}-(\nu+\mu+\delta) C .
\end{gathered}
$$

Since the (21)-(23) system describe only the disease new cases production and the changing in already existing infected states, it will be adopted as the infected subsystem. Therefore, the linearized infection subsystem can be decomposed by the Jacobian matrix $(T+\Sigma)$. Let $x^{T}=\left(I_{m}, I_{f}, C\right)$, the linearized infection subsystem 
will be [6]

$$
\dot{x}=(T+\Sigma) x .
$$

So,

$$
T=\left[\begin{array}{ccc}
0 & \alpha_{1} N_{1} & 0 \\
\alpha_{2} N_{2} & 0 & 0 \\
0 & 0 & 0
\end{array}\right]
$$

and

$$
\Sigma=\left[\begin{array}{ccc}
-\left(r_{1}+\beta_{1}+\mu\right) & 0 & 0 \\
0 & -\left(r_{2}+\beta_{2}+\mu\right) & 0 \\
\beta_{1} & \beta_{2} & -(\nu+\mu+\delta)
\end{array}\right]
$$

Note that, the infected states can be treated with the indices $i$ and $j$. Thus, the entries in $T_{i j}$ can be interpreted as the rate at which an infected individual in state $j$ produces an infected individual in state $i[6]$.

Once NGM is defined as $K=-T \Sigma^{-1}$ and $\Sigma$ is a non-singular matrix [8]. So,

$$
\Sigma^{-1}=\left[\begin{array}{ccc}
\frac{-1}{\left(r_{1}+\beta_{1}+\mu\right)} & 0 & 0 \\
0 & \frac{-1}{\left(r_{2}+\beta_{2}+\mu\right)} & 0 \\
\frac{-\beta_{1}}{\left(r_{1}+\beta_{1}+\mu\right)(\nu+\mu+\delta)} & \frac{-\beta_{2}}{\left(r_{2}+\beta_{2}+\mu\right)(\nu+\mu+\delta)} & \frac{-1}{(\nu+\mu+\delta)}
\end{array}\right] .
$$

then,

$$
K=\left[\begin{array}{ccc}
0 & \alpha_{1} N_{1} & 0 \\
\alpha_{2} N_{2} & 0 & 0 \\
0 & 0 & 0
\end{array}\right] \times\left[\begin{array}{ccc}
\frac{1}{\left(r_{1}+\beta_{1}+\mu\right)} & 0 & 0 \\
0 & \frac{1}{\left(r_{2}+\beta_{2}+\mu\right)} & 0 \\
\frac{\beta_{1}}{\left(r_{1}+\beta_{1}+\mu\right)(\nu+\mu+\delta)} & \frac{\beta_{2}}{\left(r_{2}+\beta_{2}+\mu\right)(\nu+\mu+\delta)} & \frac{1}{(\nu+\mu+\delta)}
\end{array}\right]
$$

However,

$$
K=\left[\begin{array}{ccc}
0 & \frac{\alpha_{1} N_{1}}{\left(r_{2}+\beta_{2}+\mu\right)} & 0 \\
\frac{\alpha_{2} N_{2}}{\left(r_{1}+\beta_{1}+\mu\right)} & 0 & 0 \\
0 & 0 & 0
\end{array}\right] .
$$

The entries in $\left(-\Sigma^{-1}\right)_{i j}$ are the expected time that an individual in state $j$ will pass to state $i$ [6]. Hence, it is evident that entries $i, j$ in $\left(-T \Sigma^{-1}\right)$ the expected number of infected offspring in state $i$ in the infection produced throughout their future infected life by an individual currently in the infected state $j$. 
Once $K$ has the following eigenvalues, [18]

$\lambda_{1}=0, \lambda_{2}=\sqrt{\frac{\left(\alpha_{1} N_{1}\right)\left(\alpha_{2} N_{2}\right)}{\left(r_{1}+\beta_{1}+\mu\right)\left(r_{2}+\beta_{2}+\mu\right)}}$ and $\lambda_{3}=-\sqrt{\frac{\left(\alpha_{1} N_{1}\right)\left(\alpha_{2} N_{2}\right)}{\left(r_{1}+\beta_{1}+\mu\right)\left(r_{2}+\beta_{2}+\mu\right)}}$.

By (17),

$$
\rho(K)=\sqrt{\frac{\left(\alpha_{1} N_{1}\right)\left(\alpha_{2} N_{2}\right)}{\left(r_{1}+\beta_{1}+\mu\right)\left(r_{2}+\beta_{2}+\mu\right)}}
$$

but, $R_{0}^{2}=1 \Leftrightarrow R_{0}=1$, so,

$$
R_{0}=\frac{\alpha_{1} \alpha_{2}}{\left(r_{1}+\beta_{1}+\mu\right)\left(r_{2}+\beta_{2}+\mu\right)} N_{1} N_{2}
$$

Consider now the (7)-(15) system. It is possible to perceive that the model presents five infection states $\left(I_{m}, I_{f}, I_{p}, I_{b}\right.$ and $\left.C\right)$. So, the infected subsystem will be:

$$
\begin{gathered}
\dot{I_{m}}=\alpha_{1} I_{f} S_{m}-\left(r_{1}+\beta_{1}\right) I_{m} \\
\dot{I}_{f}=\alpha_{2} I_{m} S_{f}-\left(r_{2}+\beta_{2}\right) I_{f} \\
\dot{I}_{p}=k I_{f}-\left(r_{2}+\beta_{2}\right) I_{p} \\
\dot{I}_{b}=\bar{k} I_{p}-\bar{\delta} I_{b} \\
\dot{C}=\beta_{1} I_{m}+\beta_{2} I_{f}+\beta_{2} I_{p}-(\nu+\delta) C .
\end{gathered}
$$

Only the $I_{m}, I_{f}$ and $I_{p}$ compartments produce new cases of infected individuals. $I_{m}$ and $I_{f}$ transmit the disease through sexual contact with healthy individuals and $I_{p}$ transmits the disease vertically, thus generating the $I_{b}$ class. Let $x^{T}=$ $\left(I_{m}, I_{f}, I_{p}, I_{b}, C\right)$ the linearized infection subsystem will be:

$$
\dot{x}=(T+\Sigma) x
$$

such that, 


$$
T=\left[\begin{array}{ccccc}
0 & \alpha_{1} S_{m} & 0 & 0 & 0 \\
\alpha_{2} S_{f} & 0 & 0 & 0 & 0 \\
0 & k & 0 & 0 & 0 \\
0 & 0 & \bar{k} & 0 & 0 \\
0 & 0 & 0 & 0 & 0
\end{array}\right]
$$

and

$$
\Sigma=\left[\begin{array}{ccccc}
-\left(r_{1}+\beta_{1}\right) & 0 & 0 & 0 & 0 \\
0 & -\left(r_{2}+\beta_{2}\right) & 0 & 0 & 0 \\
0 & 0 & -\left(r_{2}+\beta_{2}\right) & 0 & 0 \\
0 & 0 & 0 & -\bar{\delta} & 0 \\
\beta_{1} & \beta_{2} & \beta_{2} & 0 & -(\nu+\delta)
\end{array}\right] .
$$

Then,

$$
\Sigma^{-1}=\left[\begin{array}{ccccc}
\frac{1}{\left(r_{1}+\beta_{1}\right)} & 0 & 0 & 0 & 0 \\
0 & \frac{1}{\left(r_{2}+\beta_{2}\right)} & 0 & 0 & 0 \\
0 & 0 & \frac{1}{\left(r_{2}+\beta_{2}\right)} & 0 & 0 \\
0 & 0 & 0 & \frac{1}{\delta} & 0 \\
\frac{\beta_{1}}{\left(r_{1}+\beta_{1}\right)(\nu+\delta)} & \frac{\beta_{2}}{\left(r_{2}+\beta_{2}\right)(\nu+\delta)} & \frac{\beta_{2}}{\left(r_{2}+\beta_{2}\right)(\nu+\delta)} & 0 & \frac{1}{(\nu+\delta)}
\end{array}\right] .
$$

So, the NGM is the same as (16),

$$
K=\left[\begin{array}{ccccc}
0 & \frac{\alpha_{2} S_{f}}{\left(r_{2}+\beta_{2}\right)} & 0 & 0 & 0 \\
\frac{\alpha_{1} S_{m}}{\left(r_{1}+\beta_{1}\right)} & 0 & 0 & 0 & 0 \\
0 & \frac{k}{\left(r_{2}+\beta_{2}\right)} & 0 & 0 & 0 \\
0 & 0 & \frac{\bar{k}}{\left(r_{2}+\beta_{2}\right)} & 0 & 0 \\
0 & 0 & 0 & 0 & 0
\end{array}\right]
$$

once $K$ has three distinct eigenvalues,

$$
\lambda_{1}=0, \lambda_{2}=\sqrt{\frac{\left(\alpha_{1} N_{1}\right)\left(\alpha_{2} N_{2}\right)}{\left(r_{1}+\beta_{1}\right)\left(r_{2}+\beta_{2}\right)}} \text { and } \lambda_{3}=-\sqrt{\frac{\left(\alpha_{1} N_{1}\right)\left(\alpha_{2} N_{2}\right)}{\left(r_{1}+\beta_{1}\right)\left(r_{2}+\beta_{2}\right.}} \text {. }
$$

So,

$$
\rho(K)=\sqrt{\frac{\left(\alpha_{1} N_{1}\right)\left(\alpha_{2} N_{2}\right)}{\left(r_{1}+\beta_{1}\right)\left(r_{2}+\beta_{2}\right)}} .
$$


Then,

$$
R_{0}=\frac{\alpha_{1} \alpha_{2}}{\left(r_{1}+\beta_{1}\right)\left(r_{2}+\beta_{2}\right)} N_{1} N_{2}
$$

\section{Numerical experiments for vertical transmis- sion model}

For numerical tests with vertical transmission, we assume the hypotheses, initial conditions and parameters used in the previous text and additionally, the fertility rate $k=1.74 / 1,000,000$ inhab. [25]; contamination rate of babies born of infected mothers $\bar{k}=0.07$ (adopted); syphilis induced death rate for babies $\bar{\delta}=0.006307$ (adopted). Additionally, following the same methodology used in the previous case, were used the initial conditions $I_{p}(0)=1,360$ and $S_{b}(0)=I_{b}(0)=0$. It should be noted that the $C$ and $R$ populations are home to the two classes of infected $\left(I_{m}\right.$ and $\left.I_{f}\right)$. Thus, $r_{1}, r_{2}, b_{1}$ and $b_{2}$ were multiplied by 0.5 in order to avoid inconsistencies. Figure 7 shows the behavior of the accumulated population of infected pregnant women, infected babies and babies death due to syphilis during the period of 1 year, such a solution denotes the growth of these populations. As in the previous experiment, the data used are for the year 2017, so the figures obtained are for 2018. Note that the results are in agreement with the official statistics observed in [23]. In fact, in 2018 there were 63,182 cases of pregnant women infected with syphilis, 26,441 cases of infected babies and 261 dead babies. So this experiment also got a plausible result when compared to real data.
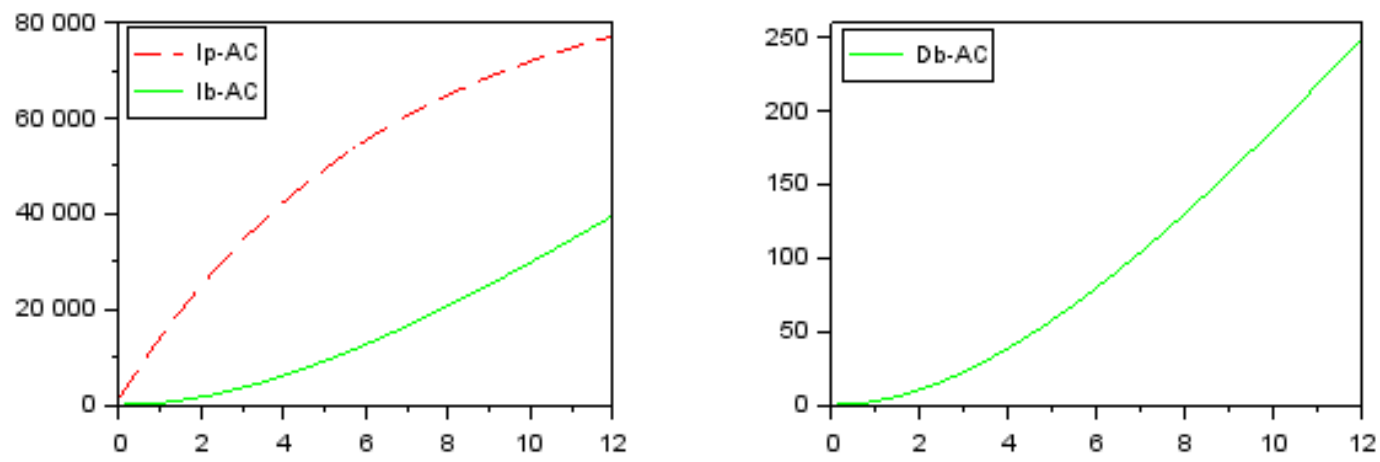

Figure 7: Numerical Solution of the Syphilis Vertical Transmission Model for Brazil in 2018. Source: Authors.

Figure 8 shows the evolution of $R(t)$. It is noted that the speed of contamination, 
in fact, decreases throughout the year, which justifies the drop in the number of cases in 2019 and the 1st semester of 2020, as found in [23]. In addition, Figure 5 confirms this fact, when the curve seen in 8 is compared to the curves for male and female infected populations, we can see that they show the same behavior. Therefore, syphilis was endemic in 2018, which means that there would be no risk of an epidemic of this disease in the near future. However, within the time of analysis (1 year), there will be no eradication of the disease. However, we must consider the limitations of the model (does not consider transmission between people of the same sex and does not consider the possibility of reinfection), the intrinsic uncertainties in the data reflected in the estimates of the rates used, and also the underreporting of cases, which we know to be an important factor. As the only effective public policy to combat the spread of syphilis in pregnant women is prenatal care [22], the result obtained may reflect a low adherence to prenatal care that leads to underreporting of cases.

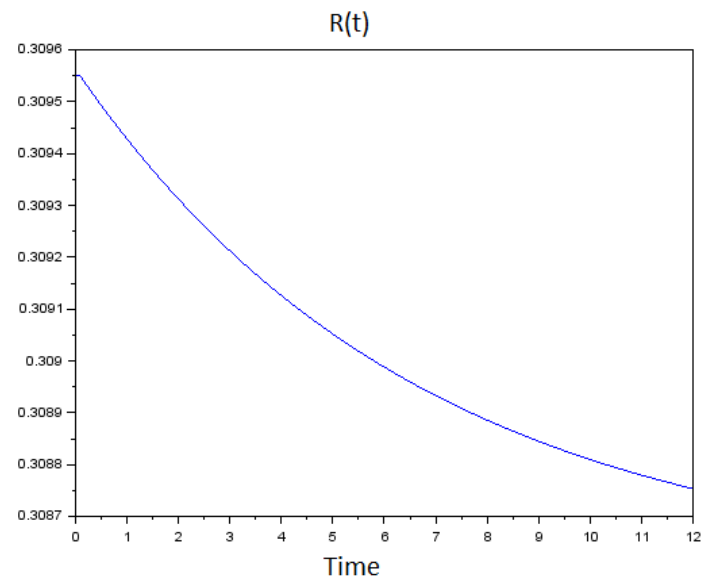

Figure 8: $R(t)$ for Vertical Transmission Model. Source: Authors.

\section{$7 \quad$ Discussions and conclusions}

Based on the models portrayed in this work, it is presented, through mathematical modeling, a tool that can help in controlling the epidemic of the disease in our country. Bearing in mind the severity of syphilis in Brazil, where the number of cases is alarming, strongly affecting the population of pregnant women [22], for example, studies that help in understanding the transmission process in the population are of great use.

Indeed, the work validated the proposed models with data publicly provided by 
the Ministry of Health [23], in addition to being able to predict the fall of cases in the following year, by calculating the $R_{0}$.

The model parameters are significant sources of uncertainty, which shows the importance for modeling of having available and reliable data and also of using safe mathematical techniques for parameter estimation. In this work, the parameters were not estimated using statistical techniques, for example, leaving for future developments the most accurate estimate of these, which will collaborate a lot with the quality of the simulations. All of this information is important to set up a plan to contain or eradicate the disease, and even set up strategies that prevent an increase in the number of deaths due to syphilis, especially in children under 1 year of age.

\section{Acknowledgments}

This study was supported by Coordenação de Aperfeiçoamento de Pessoal de Nível Superior - Brasil (CAPES) [Finance Code 001].

\section{References}

[1] ABDUllahi, A. A.; OYEnIYI, R. B.; AKITUNDE, M. A. On existence and uniqueness of Syplilis model. Mathematical Modeling and Applications, 1(2), p. 55-58, 2016. doi: 10.11648/j.mma.20160102.14.

[2] AVELleiRA, J. C. R.; BOtTinO, G. Sífilis: diagnóstico, tratamento e controle. An. Bras. Dermatol. v.81. no.2. Rio de Janeiro. Mar./Apr. 2006. doi: 10.1590/S0365-05962006000200002.

[3] BURDEN, R. L.; FAIRES, J. D. Numerical Analysis Ninth Edition. Boston, Brooks/Cole, 2010.

[4] DERRICK, N.; GROSSMAN, S. Differential Equations with Applications. Philippines, Addison Wesley Publishing Company, Inc, 1976.

[5] Diekmann, O., HeESTERBEeK, J. A. P., MetZ, J. A. J. On the definition and the computation of the basic reproduction ratio $R_{0}$ in models for infectious diseases in heterogeneous populations.J. Math. Biol. 28, p. 365-382, 1990. doi: $10.1007 / \mathrm{BF} 00178324$.

[6] DiEkMAnN, O.; HeESTERBEEK, J. A. P.; ROBERTS, M. G. The construction of next-generation matrices for compartmental epidemic mod- 
els. Journal of the Royal Society Interface 7, p. 873-885, 2009. doi:10.1098/rsif.2009.0386.

[7] van den DRIESSCHE, P.; WATMOUGH, J. Further Notes on the Basic Reproduction Number. In: BRAUER, F.; DRIESSCHE, P.; WU, J. Mathematical Epidemiology. Lectures Notes in Mathematics vol. 1945. Berlin Heidelberg, Springer, p. 159-178, 2008. doi: 10.1007/978-3-540-78911-6-6.

[8] van den DRIESSCHE, P.; WATMOUGH J. Reproduction numbers and subthreshold endemic equilibria for compartmental models of disease transmission. Mathematical Biosciences, 180, p. 29-48, 2002.

[9] FARHI, D.; DUPIN, N. Origins of Syphilis and management in the immunocompetent patient: facts and controversies. Clinics in Dermatology, 28(5), p. 533-538, 2010.

[10] GarnetT, G. P.; ARAL, S. O.; HOYle, D. V.; CATES, W. J.; ANDERSON, R. M. The natural history of syphilis: Implications for the transmission dynamics and control of infection. Sexually Transmited Diseases, p. 185200, 1997.

[11] GRASSLY, N. C.; FRASER, C.; GARNETT, G. P. Host immunity and synchronized epidemics of syphilis across the United States. Nature V 433, 2005, p. $417-421$.

[12] GUMEL A. B.; LUBUMA J. M. S.; SHAROMI O.; TEREFE Y. A. Mathematics of a sex-structered model for syphilis transmission dynamics. Math Meth Appl Sci, p. 1-25, 2018. doi: 10.1002/mma.4734.

[13] HETHCOTE, H. W. The Mathematics of Infectious Diseases. SIAM Review's V. 42 No. 4, p. 599-653, 2000. doi: 10.1137/S0036144500371907.

[14] IBOI, E.; OKUONGHAE, D. Population dynamics of a mathematical model for syphilis. Applied Mathematical Modelling, p. 1-33, 2015. doi: 10.1016/j.apm.2015.09.090.

[15] KERMACK, W. O.; MCKENDRICK A. G. A. Contribution to the mathematical theory of epidemics. Proc. R. Soc. Lond. A., 1927. Available from:<https://doi.org/10.1098/rspa.1927.0118>. Access: 2020 august 13.

[16] de KRUIF, P. Ch. 7. Schaudinn: The pale horror. Men Against Death. New York, Harcourt, 1932. 
[17] LIMA, B. G. C. Mortalidade por sífilis nas regiões brasileiras, 19801995. J. Bras. Patol. Med. Lab. v. 38, n. 4, 2002. Available from:<https://doi.org/10.1590/S1676-24442002000400004>. Access: 2020 august 13 .

[18] LIPSCHUTZ, S.; LIPSON, M. L. Álgebra Linear, 4. ed., Porto Alegre, Bookman, 2011.

[19] MILNER, F.; ZHAO, R. A New Mathematical Model of Syphilis. Mathematical Modelling of Natural Phenomena, 2010, p. 1-17. doi: 10.1051/mmnp/20105605.

[20] MS. Ministério da Saúde, Secretaria de Vigilância em Saúde. Boletim Epidemiológico Sífilis 2019. Número Especial, 2019.

[21] MS. Ministério da Saúde, Secretaria de Vigilância em Saúde, Programa Nacional de DST/AIDS. Diretrizes para controle da sífilis congênita: manual de bolso. 2. ed., Brasília, 2006.

[22] MS. Ministério da Saúde, Secretaria de Vigilância em Saúde, CoordenaçãoGeral de Desenvolvimento da Epidemiologia em Serviços. Guia de Vigilância em Saúde. v.2, 1. ed., Brasília, 2017.

[23] MS/SVS/DCCI. Indicadores e Dados Básicos da Sífilis nos Municípios Brasileiros. Available from:<https://indicadoressifilis.aids.gov.br $>$. Access: 2021 april 05.

[24] OKUONGHAE, D.; GUMEL A. B.; IKHIMWIN B. O.; IBOI E. Mathematical Assessment of the Role of Early Latent Infections and Targeted Control Strategies on Syphilis Transmission Dynamics. Springer Nature B.V., 2018. doi: 10.1007/s10441-018-9336-9.

[25] The World Bank. Fertility rate, total (births per woman) - Brazil. Available from: $<$ https://data.worldbank.org/indicator/SP.DYN.TFRT.IN?locations=BR $>$. Access: 2020 november 24.

[26] WHO. World Health Organization. TDR Disease Watch Focus: Syphilis. Available from: $<$ https://www.who.int/tdr/publications/disease_watch/syphilis/en/>. Access: 2020 august 13. 